\title{
Primer registro fotográfico de murciélagos hematófagos Desmodus rotundus (Chiroptera: Phyllostomidae) alimentándose de Odocoileus virginianus (Artiodactyla: Cervidae) en la Reserva de la Biosfera Tehuacán-Cuicatlán, México
}

Eva López Tello-Mera

Red de biología y conservación de vertebrados, Instituto de Ecología A. C., Xalapa, Veracruz, México. eera_4@yahoo.com.mx

Salvador Mandujano

Red de biología y conservación de vertebrados, Instituto de Ecología A. C., Xalapa, Veracruz, México.

Los murciélagos hematófagos se distribuyen en Latinoamérica, desde México hasta el norte de Argentina (Greenhall et al. 1983, Greenhall et al. 1984, Greenhall \& Schutt 1996). Estos murciélagos contribuyen a regular las poblaciones de fauna silvestre de las que se alimentan (González Christen 2003). Las especies Diphylla ecaudata y Diaemus youngi también contribuyen en el mantenimiento de la salud de las poblaciones ya que solo atacan individuos débiles o enfermos (Horváth 2010). De las tres especies (D. ecaudata, D. youngi y Desmodus rotundus) que se distribuyen en México, D. rotundus es la más común y la que se alimenta de diversas especies de mamíferos silvestres, así como de ungulados domésticos (Johnson et al. 2014). También se considera como una de las principales especies hospederas y transmisoras de la rabia (Correa-Scheffer et al. 2014).

La rabia es una enfermedad zoonótica causada por el virus del género Lyssavirus de la familia Rhabdoviridae (Tordo et al. 1998). Tanto en México como en otros países, se ha documentado que mamíferos como Procyon lotor, Urocyon cinereoargenteus, Mephitis spp., Canis latrans, entre otros, pueden ser hospederos y transmisores de este virus (Flores-Crespo 1998, Bengis et al. 2004). Debido a la deforestación y al aumento del ganado, en los últimos años también se ha documentado un incremento en la abundancia de D. rotundus ya que, entre otros factores, tiene mayor disponibilidad de alimento (Johnson et al. 2014). Actualmente, la rabia representa un problema para el sector ganadero porque $D$. rotundus prefiere alimentarse del ganado, por lo cual hay mayor probabilidad de que sea infectado por el virus (Mayen F. 2003) y se produzcan grandes pérdidas económicas (Ortega Chávez et al.2009).

En la Reserva de la Biosfera Tehuacán-Cuicatlán habita D. rotundus (Rojas-Martínez \& Valiente-Banuet 1996, Briones-Salas 2000) y hasta antes del año 2012 no se había reportado que ésta especie se alimentara del Venado Cola Blanca (Odocoileus virginianus). Durante el proyecto de monitoreo de Venado Cola Blanca en la Reserva de Tehuacán-Cuicatlán (Ramos-Robles et al. 2013), en una de las localidades de estudio se obtuvieron dos registros con cámaras trampa digitales (Primos TruthCam 35®), de murciélagos hematófagos alimentándose de O. virginianus. La primera el 13 de octubre a las $23 \mathrm{~h} 35$ (Figura 1A) y la segunda el 15 de octubre a las $03 \mathrm{~h} 14$ (Figura 1B), en la misma cámara(N1800' 24", E9702'06"). También seobtuvieron registros de murciélagos hematófagos alimentándose del ganado en esta y en otras dos cámaras (N18 00' 46", E 97 01'43"; N18 $00^{\prime} 38^{\prime \prime}$, E $\left.97^{\circ} 01^{\prime} 56^{\prime \prime}\right)$, (Figura 1C, 1D).

En México, el Venado Cola Blanca es utilizado por los pobladores locales como una fuente de proteína animal, así como trofeo por los cazadores deportivos (Mandujano \& Rico-Gray 1991, González-Perez \& Briones-Salas 2000, Naranjo et al. 2004). Por lo tanto, es necesario realizar estudios y análisis sobre las implicaciones biológicas, ecológicas y zoonóticas que pudiera tener la interacción entre murciélagos hematófagos y otras especies silvestres en esta región (Ortiz-Garcia et al. 2012, Cruz-Jácome et al. 2015), similar a lo que sucede con otros parásitos en zonas tropicales (Romero-Castañón et al. 2008).

Mammalogy Notes | Notas Mastozoológicas

Sociedad Colombiana de Mastozoología

Vol. 3 Num. 1| 2016 


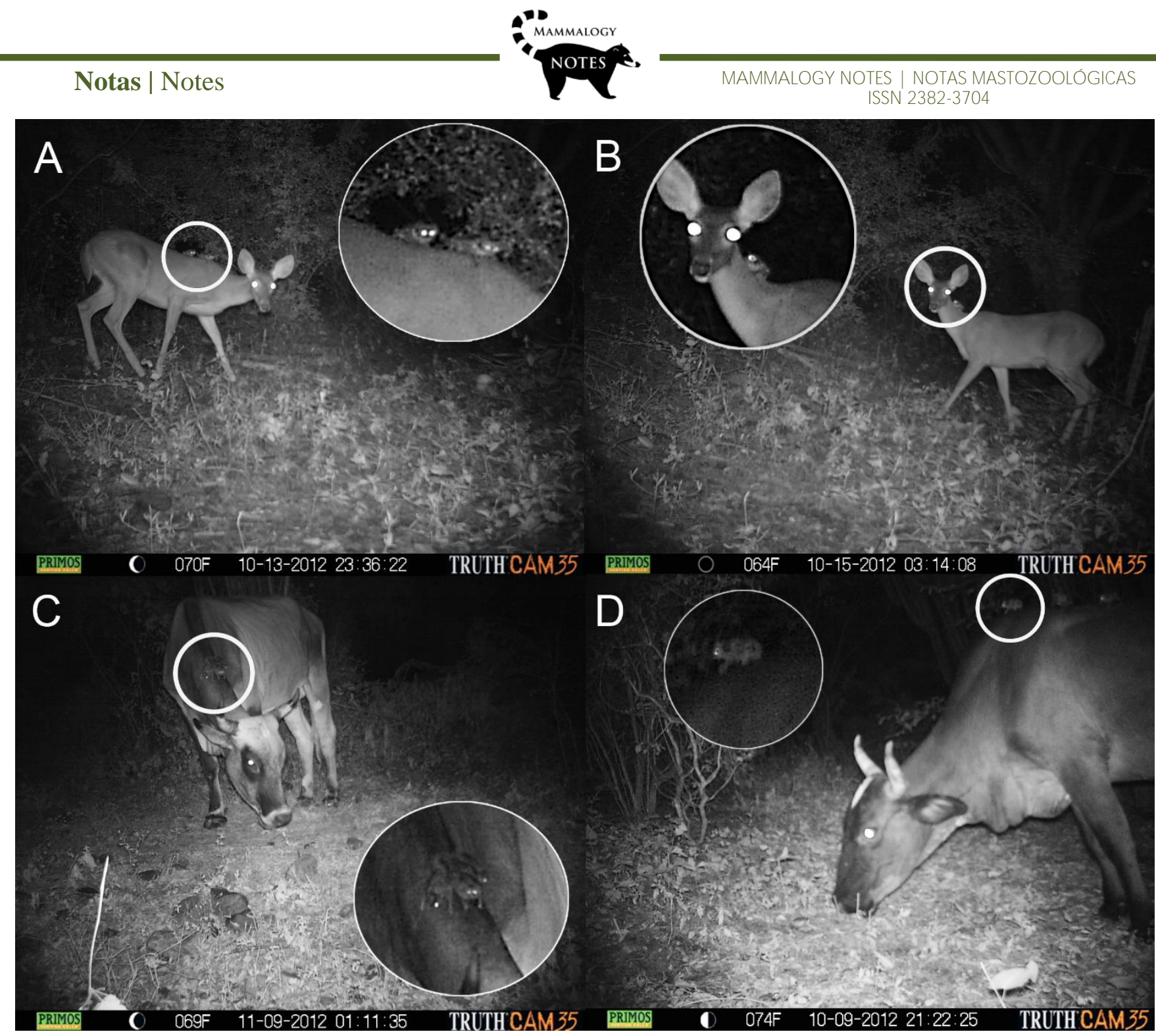

Figura 1. Registros fotográficos de venados Odocoileus virginianus (A, B) y ganado (C, D) en los que se observa a murciélagos hematófagos alimentándose.

Agradecimientos

Se agradece al CONACYT por el financiamiento otorgado para la compra de cámaras-trampa y el monitoreo en campo en el marco del proyecto CB-2009-01 No. 130702 “Evaluación de las interacciones entre el venado cola blanca y el ganado en la Reserva de Biosfera de Tehuacán-Cuicatlán: implicaciones de conservación y manejo".

\section{References}

BENGIS, R. G., et al.2004. The role of wildlife in emerging and re-emerging zoonoses. Scientific and technical review of the office international des epizooties 23: 497-511. CORREA SCHEFFER, K., et al. 2014. Murciélagos hematófagos como reservorios de la rabia. Revista Peruana de Medicina Experimental y Salud Pública 31 : $302-309$.

BRIONES-SALAS, M. 2000. Lista anotada de los mamíferos de la región de la Cañada, en el Valle de Tehuacán-Cuicatlán, Oaxaca, México. Acta Zoológica Mexicana (n. s.) 81:83-103.

CRUZ-JÁCOME, O., et al. 2015. Riqueza y abundancia relativa de mamíferos medianos y grandes en una localidad en la Reserva de la Biosfera Tehuacán-Cuicatlán, Oaxaca, México. Therya 6: 435-448.

FLORES-CRESPO, R. 1998. Ciclos de rabia en la fauna silvestre y su importancia epidemiológica. En: La rabia en las diferentes especies, sus transmisores y su control (FloresCrespo R., Ed.). Instituto Nacional de Investigaciones Forestales Agrícolas y Pecuarias. México, D.F., México.

GONZÁLEZ-CHRISTEN, A. 2003. De vampiros a vampiros. Foresta Veracruzana [en línea] 2003, 5: Disponible en:<http://www.redalyc.org/articulo.oa?id=49750109> ISSN 1405-7247. Fecha de consulta: 6 de octubre de 2015.

GONZÁLEZ-PÉREZ, G. \& M. BRIONES-SALAS. 2000. Venado cola blanca (Odocoileus virginianus) en comunidades indígenas de Oaxaca. Investigación Hoy 94: $20-27$. GREENHALL, A. M., et al. 1983. Desmodus rotundus. Mammalian Species, 202: 1-6.

GREENHALL, A. M., et al. 1984. Dyphilla ecaudata. Mammalian Species, 227: 1-4

GREENHALL, A. M. \& W. A. SCHUTT W. 1996. Diaemus youngi. Mammalian Species, 533: 1-7.

\section{Mammalogy Notes | Notas Mastozoológicas \\ Sociedad Colombiana de Mastozoología \\ Vol. 3 Num. 1| 2016}


HORVÁTH, A. 2010. Enemigos o aliados: pautas para la investigación y conservación de murciélagos. Ecofronteras, [S.1.]: 22-25. Disponible en: <http://200.23.34.40/ecofronteras/index.php/eco/article/view/810>. Fecha de acceso: 09 octubre 2015

JOHNSON, N., et al. 2014. Vampire bat rabies: Ecology, epidemiology and control. Viruses 6: 1911-1928,doi: 10.3390/v6051911.

MANDUJANO, S. \& V. RICO-GRAY. 1991. Hunting use and knowledge of the biology of the White-tailed deer (Odocoileus virginianus Hays) by the Maya of central Yucatan, Mexico. Journal of Ethnobiology 11: 175-183.

MAYEN, F. 2003. Haematophagus bats in Brazil, their role in rabies transmission, impact on public health, livestock industry and alternatives to an indiscriminate reduction of bat population. Journal of Veterinary Medicine Series B 50: 469-472.

NARANJO, E. J., et al. 2004. Subsistence hunting by three ethnic groups of the Lacandon forest, México. Journal of Ethnobiology 24: $233-253$.

ORTEGA-CHÁVEZ, V., et al. 2009. Estudio retrospectivo de la rabia en animales de importancia económica en el Estado de Puebla, México del año 2001 al 2008. Revista electrónica de veterinaria 9: Disponible en: <http://www.veterinaria.org/revistas/redvet/n090909.html>ISSN: 1695-7504.Fecha de consulta 6 de octubre de 2015.

ORTIZ-GARCÍA, A.I., et al. 2012. Distribución potencial de los ungulados silvestres en la Reserva de Biosfera de Tehuacán-Cuicatlán, México. Therya 3: 333-348.

RAMOS-ROBLES, M., et al. 2013. Habitat and human factors associated with white-tailed deer density in the tropical dry forest of Tehuacán-Cuicatlán Biosphere Reserve, Mexico. Tropical Conservation Science 6: 70-86.

ROJAS-MARTÍNEZ, A. E. \&A. VALIENTE-BANUET. 1996. Análisis comparativo de la quiropterofauna del Valle de Tehuacán-Cuicatlán, Puebla-Oaxaca. Acta Zoológica Mexicana (n. s.) 67:1-23

ROMERO-CASTAÑÓN, S., et al. 2008. Comparative parasitology in wild and domestic ungulates in the Selva Lacandona, Chiapas, Mexico. Comparative Parasitology 75:115126.

TORDO N., et al. 1998. Rhabdoviruses: rabies. Pp. 666-692 InTopley and Wilson's Microbiology and Microbial Infections (Collier L.H., ed.), Arnold Press, London, England. 